\section{Extracted leaf protein in British agriculture}

SIR - Extracted leaf protein (LP) is not made commercially in Britain and there is little research on it here. It is made commercially in Denmark, France, Italy, Japan, New Zealand, Poland, Spain, the United States and the Soviet Union. Because it is possible that it is we who are out of step, it seems timely to reconsider the arguments for LP production.

No one has questioned the argument, advanced more than 40 years ago and amply confirmed experimentally since, that the annual yield of protein in the form of LP can be greater than the yield of a protein concentrate by any other type of farming. Similarly, the demonstrations that LP can replace fishmeal or soy in pig and poultry diets, made 20 years ago in the National Institute for Research in Dairying and the Rowett Research Institute, have been confirmed in many other institutes. The residue remaining after protein extraction contains less water than any crop normally dried for conservation as winter feed for ruminants. Logically therefore, drying should be economical. There is ample evidence that the residue, because non-nitrogenous material is extracted as well as protein, still contains 1.5 to $2.0 \% \mathrm{~N}$ (in the dry matter) and that it makes good silage from which there is no wasteful and polluting effluent. This residue, whether fresh, dried, or ensiled is readily eaten by ruminants. Many experiments show that its feeding value is, weight for weight, as great as that of the original crop: this is presumably because more of the $\mathrm{N}$ in it is true protein and because comminution makes it more readily digestible.

One reason for the relative lack of interest in Britain in the use of LP as an animal feed, is the emphasis that has been put here on its value as a human food in countries with a humid climate and protein deficiency. As a result of successful human feeding trials, there are in these countries several production units managed by local enterprise rather than by sponsorship from outside. Its value and acceptability are now established. Even vegetarians in Britain usually eat diets containing an adequate amount of protein. There is therefore little need here for this application of LP. However, we feed pigs and poultry on imported fish meal, ground nut meal and soya: these could be largely replaced by home-produced LP. That substitution would not exacerbate the widely condemned overproduction of agricultural products. On the contrary, while economizing on imports, it would offer farmers an alternative to those crops which are now over-produced.

Another reason for lack of interest is that insufficient attention has been paid to the number of potential sources of LP. In early work at Rothamsted, a dozen suit- able sources were described: the list could be extended, and it has been further extended in tropical countries. But in most countries where there is commercial production, attention is confined to grass mixtures and lucerne. The latter is agronomically attractive, but its juice froths inconveniently and, unlike some other species, it yields LP with an unappealing flavour. LP can also be extracted from byproducts such as potato haulm, sugar beet tops and vegetable discards. If effort were put into collection, by-products could supply 100,000 tons of protein anually in Britain as well as a residue suitable for cattle feed.

Yet another reason for lack of interest is the use of unsuitable equipment and techniques in such large-scale trials as have been made. High-speed pulping equipment was used in early work at Rothamsted because we were sure it would work: it is still the most satisfactory equipment in agronomic studies. But pulping by slow-speed rubbing, or extrusion through a die, uses less power and is nearly as effective. If the pulp is less than $1 \mathrm{~cm}$ thick after pressing, and if pressure is maintained for a few seconds, juice expression is satisfactory with 1 to $2 \mathrm{~kg}$ force per $\mathrm{cm}^{2}$ (100 to $\left.200 \mathrm{kPa}\right)$. The vast screw expellers, which have been used in some unsuccessful trials, are extravagant and perform poorly because tightly packed fibre impedes the outflow of protein-rich juice. There are simpler and cheaper methods for expressing juice: more should be devised, for this is the least satisfactory part of the process.

Lack of success in feeding trials with unfractionated juice was predictable. Its protein content is small and variable, its cation content is often excessive and, with some species of leaf, it contains unappealing or slightly toxic components. When a production routine has been established, there is no need to separate coagulated LP completely from the juice. If the coagulum is allowed to settle, the sediment has a relatively constant composition, and the supernatant carries away most of the deleterious material. Furthermore, if conservation is necessary because of an uneven supply of leaf, the compact sediment needs less of the preservative. Heating is preferable to any other method of coagulation. It is an illusion to regard it as expensive. Much of the necessary heat can, with a counter-current arrangement, be supplied by juice which has already been heated. If the pulper is driven by a diesel or steam engine on site, exhaust heat will be more than adequate for coagulation.

Without an estimate of costs, the place of LP in British agriculture cannot be assessed. Costs are obviously inflated when the equipment used is more elaborate and expensive than necessary, and when the value of the residual fibre as cattle feed, and the possible value of the fluid which is separated from the coagulum, are not included in the calculation. So many factors tend to invalidate the gloomy conclusions drawn from trials which made inadequate use of existing knowledge and experience, that it was premature to decide that LP production would not be advantageous in Britain. No one has rebutted the basic propositions on which advocacy of LP production depends. The objective is sound, but execution has hitherto been faulty.

Rothamstead Experimental Station, Harpenden, Herts ALS $2 J Q, U K$

\section{Calmodulin and eukaryote evolution}

SIR-Whilst reading the recent report by Sudhaker Babu et al.' on the threedimensional structure of calmodulin, I was again impressed by this protein's ubiquitous role in eukaryotes. From cotton seed to rat testis it shows itself in a remarkably constant condition and appears to show that a similar ancestor must have been present at the dawn of eukaryote evolution.

Rightly or wrongly the next step is to review the prokaryotes for 'ancestral types' and Escherichia coli ${ }^{2}$ has a contender in the form of the acyl/carrier protein which has a section resembling that of the E-F hand ${ }^{3}$ structure. Also, the antibiotic amphyomycin has been shown ${ }^{4}$ to have a calcium dependent action upon Gram-positive bacteria. Its structure $^{5}$ shows it not to contain an E-F hand (it only contains 11 residues) but at least a second finger, that is, the loop of the helix-loop-helix described by Kretsinger and Barry ${ }^{3}$.

If the evolutionary link between Streptomyces antibiotic production and eukaryote calmodulin seems far-fetched, does this mean that the second finger of the E-F hand is the only decent way to employ amino acids in the capture of calcium ions?

School of Biological Sciences,

University of East Anglia,

Norwich NR4 7TJ, UK

1. Sudhakar Babu, Y. et al. Nature 315, 37-40 (1985)

. Vanaman, T. C., Wakil, S. J. \& Hill R. L. J. biol. Chem. 243, 6427-6431 (1968)

Kretsinger, R. H. \& Barry, C. D. Biochim. biophys. Acte 405, 40-52 (1975)

Matsui, M., Oka, Y. \& Araki, T. J. Antibiot. A16, 7-11 (1963)

Bodiansky, M., Sigler, G. F. \& Bodansky, A. J. Am. chem Soc. 95, 2352-2357 (1973)

\section{Scientific Correspondence}

Scientific Correspondence is intended to provide a forum in which readers may raise points of a rather technical character which are not provoked by articles or letters previously published (where Matters Arising remains appropriate). 